\title{
Expounding the Role of Exercise in the Management of Type II Diabetes 體育運動在改善 II 型糖尿病中的作用
}

\author{
Michael CHIA Jin Jong QUEK
}

Physical Education and Sports Science Academic Group, National Institute of Education, Nanyang Technological University, SINGAPORE

\author{
謝录和 郭仁勇 \\ 新加坡南洋理工大學 \\ 國立敉育學院體育與運動科學組
}

\begin{abstract}
The association between the urbanization of cultures and the concomitant decreased levels of exercise and physical activity and the prevalence of type II diabetes has been established. The incidence of type II diabetes in Singapore is about six percent in the adult population but the disease is unequally distributed among the ethnic cultures. Type II diabetes is also linked with an increase in age, body weight and body fat, but a regimen of regular aerobic-type or light intensity weight-training has 'insulin-like' effect and is beneficial in the amelioration and management of type II diabetes. However, the 'insulin-like' are quickly lost within 14 days after the cessation of the exercise training or physical activity.
\end{abstract}

\section{摘 要}

現已確認城市的都市化伴隨著體育活動的水平下降, 並與 II 型糖尿病的流行之間有著相互的聯系。II 型糖尿病在新加坡成年人 中的發病率約為 $6 \%$, 但疾病的分佈在不同的種族之間是不均衡的。II型糖尿病也與年龄的增長, 體重和體脂的增加有關。規律性和 系統性的有氧或健身運動可產生“胰島素樣”作用, 這有利于改善桾尿病病人的狀況。然而, 運動訓練或體育活動一旦停止, 此“胰 島素樣” 作用即在 14 天內消失。

\section{Introduction}

Glucose is a primary source of energy for the brain and a decrease in the concentration of glucose in the blood in the fasted state or during prolonged exercise has been implicated as a cause of central fatigue. Yet the amount of glucose in the blood has to be maintained within narrow limits for the proper functioning of the body. Glucose concentration in the blood is maintained by the processes that add glucose to the blood in the form of ingested food and drink, and by the processes that remove glucose form the blood in the form of tissue uptake of glucose by the nervous system and also tissues in the periphery (Ivy, Zdervic, \& Fogt, 1999).

Following a meal, blood glucose level increases and must be kept under control by the hormone insulin, which is secreted from the pancreas. Diabetes is a disease whereby the body is unable to regulate the concentration of glucose in the blood and where the body is impaired in its ability to break down and use glucose, a simple form of carbohydrate. There are two 
main forms of the disease-insulin-dependent diabetes mellitus (IDDM or type I) and non-insulin-dependent diabetes mellitus (NIDDM or type II).

Type I diabetes or IDDM is a disease that afflicts a small proportion of all cases of diabetes. It has been estimated that about $5-10 \%$ of diabetes is IDDM and this form of the diseases occurs mainly in young people (Chia, Leong, \& Quek, 2002). In IDDM, the pancreatic beta cells that produce insulin are destroyed and the body is unable to produce sufficient amounts of insulin. People with IDDM require daily injections of insulin for life to help with glucose metabolism and although they can benefit from an appropriately structured programme of regular exercise, a physically active lifestyle will help improve the quality of life but it will not cure or prevent this form of the disease.

Type II diabetes or NIDDM, on the contrary, is the more prevalent form of diabetes and accounts for $90-95 \%$ of all cases of the disease (Chia, Leong, \& Quek, 2002). In this form of the disease, the body is impaired in its response to insulin (i. e. insulin resistance) and sometimes there is insulin insufficiency as well (Ivy, Zdervic, \& Fogt, 1999). Type II diabetes is more prevalent in adults aged 40 years and above and is associated with an increase in body weight. It is observed that over $80 \%$ of people with NIDDM are overweight or obese (Zierath \& Walberg-Henriksson, 1992).

Research informs us that type II diabetes is associated with a sedentary lifestyle, but the disease is amenable to the effects of exercise and increased physical activity (Manson et al, 1992). In Singapore, the prevalence of type II diabetes in the population is nine percent but the disease is unequally distributed among ethnic groups, with Indians having the highest proportion (15. $8 \%$ ), followed by Malays (11.3\%) and then the Chinese (8.0\%) (National Health Survey, 1998).

\section{Diagnosis of NIDDM}

Clinically, NIDDM is defined as an eight-hour fasting blood glucose level that exceeds $126 \mathrm{mg} / \mathrm{dl}$ or a two-hour oral glucose tolerance test where the glucose concentration in the blood exceeds 199 mg/dl. (Wallberg-Henriksson, Rincon \& Zierath, 1998). A predominate characteristic of type II diabetes and one that precedes the disease, however, is insulin resistance or impaired glucose homeostasis. In this condition, the blood glucose level is higher than normal and is between $110 \mathrm{mg} / \mathrm{dl}$ and less than $126 \mathrm{mg} /$ $\mathrm{dl}$ for an eight-hour fast, or where the result of a two-hour oral glucose test result, is between $140 \mathrm{mg} / \mathrm{dl}$ and less than 199 mg/dl (Wallberg-Henriksson, Rincon, \& Zierath, 1998). Both impaired glucose homeostasis and type II diabetes are associated with an increased risk of developing atheroscelerosis (i.e. narrowing of the blood vessels due to the formation of plaque), hypertension (high blood pressure), heart disease, stroke and other forms of micro-vascular disease like retinopathy and blindness. There is also an increased risk of infection. Such conditions, when present severely reduce the quality of life and also life expectancy.

\section{The Effect of Exercise, Increased Physical Activity and the Amelioration and Management of NIDDM}

Given that older people have a higher incidence of NIDDM and consistent with prudent guidelines for embarking upon any exercise programme, it is important that people with NIDDM be given a complete physical checkup to rule out any longterm complications of diabetes. All individuals above the age of 35 years should perform an exercise stress test before engaging in any exercise that requires moderate to vigorous physical exertions (Walberg-Henriksson, Rincon, \& Zierath, 1998).

Research evidence is consistent in showing that the increased prevalence of impaired glucose metabolism and NIDDM, go hand in hand with the urbanisation of various cultures where there is a prevalence of physical inactivity. For example, improved glucose tolerance in urbanised Australian aborigines was shown when the subjects returned to their traditional hunter-gatherer lifestyle. Other researchers have reported better glucose tolerance and an amelioration of NIDDM in more physically active populations compared to their more sedentary peers. Research data on the efficacy of exercise in the treatment of glucose intolerance are buttressed by a series of studies conducted by Manson and his colleagues in the 1990s. In one of their studies, the risk of developing NIDDM was substantially less in female subjects who were engaged in vigorous exercise once a week, compared to subjects who exercised less frequently, even after adjusting for differences in Body Mass Index (Manson, Rimm, \& Stampher, 1991) In another study, Manson et al, reported that male doctors who exercised vigorously five times a week exhibited a $42 \%$ lower risk of developing age-adjusted NDDM than those who exercised less than once a week. The results were more evident in subjects who were overweight (Manson, Nathan, \& Krolewski, 1992) Some studies showed that although exercise training brought out improved glucose tolerance, the gains were very quickly lost over just 10 days of inactivity (Kriska, 2000). It appears therefore that it is the continuance of exercise that is beneficial in the amelioration of type II diabetes since regular exercise has an 'insulin-like' effect on the body. 


\section{Young People in Comparison to Older People}

There is a strong association between aging and the development of insulin resistance, which might explain the increased prevalence of glucose intolerance and NIDDM among the elderly. Even then, the impairment of insulin in older people may not be due to aging per se. It appears that up to 70 years, insulin action is determined more by changes in lifestyle such as increased physical inactivity, a poor diet and an increase in body weight and body fat than by aging. Indeed, the elderly who are exercisetrained, and are leaner, have enhanced insulin action, when compared to the untrained elderly (Chia, Leong, \& Quek, 2002).

Young healthy athletes who maintain a physically active lifestyle typically have a reduced insulin response to a glucose challenge. Similar responses have been documented for athletes who engage in aerobic-type training and also in athletes who weight-train (Chia, Leong, \& Quek, 2002). The 'insulin-like' effect of regular exercise is evident within seven days of training, but the benefits are also quickly lost with the cessation of training.

\section{Conclusion}

The benefits of a physically active lifestyle and exercise training in the prevention and treatment of NIDDM are robustly supported by both current and past research. Even though the mechanisms involved are complex and not entirely understood, it appears that changes occur at the systemic, tissue and cellular levels. The adaptations that occur with exercise training or regular physical activity are quickly lost within 14 days of the cessation of the training or activity, thus emphasising that a physically active lifestyle must be maintained for the protective benefits to be sustained. It appears that exercise programmes that involve large muscle groups such as walking, swimming, cycling and weight training are advantageous for the prevention and treatment of insulin resistance in NIDD in both the young and the elderly, but the importance of the regularity and continuance of the exercise training or physical activity cannot be over-emphasised.

\section{References}

Chia, M., Leong, L.K.. \& Quek J.J. (2002). Healthy, Well and Wise, (2nd ed.) National Institute of Education. Singapore.

Ivy, J, Zdervic, T., \& Fogt, D. (1999). Prevention and Treatment of Non-Insulin-Dependent Diabetes Mellitus. Exercise and Sports Sciences Reviews, 27, 1-35.

Kriska, A. (2000). Physical activity and the prevention of type 2 diabetes mellitus: how much and for how long? Sports Medicine, 29, 147-151.

Manion, J., Nathan, D., \& Kroleski, A. (1992). A prospective study of exercise and incidence of diabetes among US male physicians, Journal of American Medical Association, 268, 63-67.

Manion, J., Rimm, E., \& Stampfer, M. (1991). Physical activity and incidence of non-insulin-dependent diabetes mellitus in women. Lancet, 338, 774-778.

National Health Survey (1998). Ministry of Health. Singapore.

Wallberg, H., Rincon, J., \& Zierath, J. (1998). Exercise in the management of non-insulin dependent diabetes mellitus. Sports Medicine, 25, 25-35.

Zierath, J., \& Wallberg-Henriksson, H. (1992). Exercise training in obese diabetic patients: special considerations. Sports Medicine, 14, 171-189.

\section{Correspondence:}

Michael Chia, Ph.D.

Physical Education and Sports Science

National Institute of Education

Nanyang Technological University.

1 Nanyang Walk,

Singapore 637616.

SINGPORE

Tel: 65-67903701 Fax: 65-68969260

Email:yhmchia@nie.edu.sg 